\section{Inside and Outside the School Gates:}

\section{Exploring} Marginalisation in KwaZulu-Natal Schools in South Africa

M i c h a e I S a m u e I w it h

Y u s u f $s$ a y e d
1 In trod u c tio $n$

Schooling is often optimistically presented as the forum in which individuals find avenues for self development, where a nation can sow and harvest the human resource potential of the future generation of society, where notions of democracy, equity and social justice are taught and learnt. Most nation-states develop their official policies around education in order to realise at least some of these psychological, social and ideological goals, yet the glaring contrary reality often presents itself. Schooling for many is not self-affirming, is unable to produce adequate and relevant human resource capital and is a place where learners learn more about the iniquitous hierarchies that exist between different groups of people. Patterns of social inequalities are reflected in schools despite the policy interventions aimed at reducing or eradicating injustices.

This study aims to uncover the experiences of learners within the schooling system in the context of a country which consciously attempted to make a break from the past history of an apartheid education system. South Africa is one of the few countries in present times which has had the fortune of being able to fundamentally overhaul its education system, infusing at all levels a campaign for realising better social justice for all. In particular, the goals of the new educational policies attempted to be reconciled with the New Constitution in the country (RSA 1996), which presented new liberties for the previously marginalised, or excluded in society. The education policy makers were nevertheless conscious that the legislating of policies would not transform the system overnight and that deliberate and sustained effort would be necessary to tackle the deep-rootedness of the past prejudices and stereotyping in the social fabric of postapartheid life. This study is conducted some eight years after the formal dismantling of the former apartheid education system. It is an opportunity to reflect on how far we have come to be able to realise the goals of better justice for the marginalised.

In the South African context, numerous studies have already investigated the deracialising phenomenon of post-apartheid schooling (Mabasa 1999; Naidoo 1996; Zafar 1999; Carrim and Sayed 1992; Freer 1991; Garson 1998; Hofmeyer 1998; Hoadly 1998; Paterson and Kruss 1998; Soudien 
1998). This project aimed to move beyond the broad macro-survey type research, which characterised many of these earlier studies. It attempts to provide a more fine-grained analysis of the lived experiences of the managers, teachers, learners and parents of learners within the specific historical and cultural context of their specific schools. This fine-grained analysis provides a deeper analysis of the professed achievements of the schooling system by looking at the day-to-day experiences of the focused participants within particular kinds of schooling.

This particular report draws from the case studies of nine schools in the largest province of South Africa, namely KwaZulu-Natal (KZN). Due to constraints of budget and time, this research could be seen as merely an exploratory study into only one geographic area within the province. The schools selected for the project were all within an urban or peri-urban setting in the Greater Durban region. The study focused on two questions: how do individuals experience and understand marginalisation/ inclusion within the schooling system? And how are educational policies designed to address diversity/ promote inclusion interpreted, understood and enacted in practice at the school level?

\section{2}

The research in KZN highlighted key features about the process of implementing inclusion education policies. The research suggests that admission to school is very much the result of geographical location favouring middle-class and white communities, with regard to entry into ex-Model C schools. The schools' attitude is very much a handsoff approach, as they tend to benefit from their geographical positioning. What is also evident is the 'migration' of white parents and learners from schools where the racial composition of learners change rapidly.

One group that was excluded from schooling were parents, except through the exacting of school fees. Thus the school fees represent the key nexus between parents and school, reflecting the inherent notion of schooling as a financial transaction (a perverse result of the policy, which argued that all parents are obligated to pay for their quality of schooling within their means available).
Parental exclusion in general reflected interesting race and class orientations. African parental involvement in the school is relatively restricted. This has to do with the view that the school is seen to be 'middle class', and as racially different. This sometimes stems from the geographic separation of the parent body from the school. By contrast, white parent involvement in such schools is fairly high. In addition, it is evident that the school controls the level of involvement through the way they respond to the School Governing Body (SGB) and how they draw it into deliberations about the school. Moreover, it is clear that there is a belief by parents, perhaps as a consequence of the collection of user fees, that teachers are primarily responsible for education and that their role is mainly to motivate the learners. Working-class parents generally are not involved in schooling.

Teachers play a crucial role in facilitating inclusion. However, the research suggests that they are increasingly becoming separate from learners on the basis of race, class and culture. Moreover, when the composition of teaching staff changes in a school from what it was previously, the 'new teachers' are marginalised with many complaining of feeling unwelcome.

More importantly, it is evident that managers and teachers consciously choose to steer a road of nonresistance as far as possible. Their strategic compliance with values and practices that they do not necessarily share, is a characteristic that allows the school to achieve a semblance of productivity or 'normalcy'. It is also evident that schools seem unable to master the development of competent second language speakers, resulting in their learners being further marginalised from the project of schooling.

In terms of learner identity, what is interesting is the pressure that working-class children face in the tension of negotiating their parents' expectations of them finding a job; and their teacher's middle-class aspirations to enter them into the academically successful careers. By contrast, middle-class children are likely to share a common world view within the home and the school set-up. They are more likely to experience schooling as affirming, even in the context of a mixed-class school setting. Learners' competence in the English language is a 
clear marker for inclusion for the teachers. Competence in English can be experienced negatively by learners within the context of a largely non-English environment, and learners who do not share this competence ostracise the competent English speaker.

3

This study has revealed that schools continue to be faced with a series of challenges to realise a transformed education system. The list of concerns below represent reflections emerging out of the study and are couched in terms of comments and questions that this study has opened up. These questions are presented as the possible agenda for future research.

A major finding of this study is that schools seem to be in need of a series of support interventions to offset the quality of marginalisation that many learners face in the day-to-day experience of schooling. Some of these support mechanisms or structures could be managed within the school itself, but more importantly in dialogue with relevant stakeholders in the Department of Education and within the community itself.

There appears to be a growing class divide that seems to characterise the schooling system. Schools in more middle-class areas are able to offer a better quality education because of the quality of financial resources that they are able to generate from the community. These financial resources are more likely to be available in middle-class communities where schools are able to offer the quality of education that the parent community desires for their children. These financial resources allow the schools to offer a more focused type of education, which is closer to the perceived needs of the parent community - for example, better teacher:learner ratios characterise these schools. It is evident that working-class communities are unable to afford the fees set by some schools and this needs to be addressed. Recent campaigns by the teacher union and trade movement to review the demand of school fees is relevant to this debate. Unless this is done, the access to good schooling will be restricted for the poor of the community. Whereas race was the organisational characteristic of the apartheid era, class will become the marker of privilege in post-apartheid South Africa.
Where these financial resources are not available, schools have to be supported by a more concerted effort from external sources, for example, the Department of Education or the business/private sector to realise an equitable education for all its citizens. This involves a review of the kind of financial support that is offered by the Department of Education to schools in different class-zoned areas. The current formulae of funding support given to poorer schools needs to be reviewed more thoroughly.

In a sense, what the current policy is generating is a two-tier schooling system, with former black schools being a second chance system for those not going to other schools and without sufficient resources to counteract the movement.

The changes to ex-White schools reveals an interesting pattern of dual migration. On the one hand, more and more Black learners are seeking admission into the former White schools. The belief of new enrolling parents is that these schools offer a better education for their children. What is noticeable is that the Black learner populations in these schools are afforded a better available pool of extra-curricular resources, which enhance the potential quality of their schooling. However, when Black learners have to travel large distances to reach the school daily, this potential is often not fully tapped into. On the other hand, former White schools seem to be noticing an exodus of White learners from its schools. The study was not able to ascertain either to where these White learners are migrating, or what factors propel this movement. However, despite the changed racial composition of the schools, the schools have remained largely unaltered in terms of the staffing composition. These staff therefore work assiduously in preserving the previous (racialised or classed) ethos of the school. This is done in some cases at the expense of not raising any voice of dissension or resistance to the changes. Teachers' jobs are on the line and therefore they are likely to accept a silencing of their resistances to the changes.

One of the more interesting policy outcomes with regards to inclusion in post-apartheid South Africa are the ways in which deracialisation has resulted in a particular pattern of parent and learner migration. In the case of former Indian schools, parents feel 
that they no longer serve the needs of the Indian community: they opt for the 'better pastures' of the former White school. This option is possible when they are able to afford the high school fees demanded by these schools. By contrast, African parents send their children to former Indian, (Coloured) or White schools. The motivation for this migration is argued largely in terms of these schools being able to offer a quality of English medium of teaching and learning. Again school fees impede this mobility. The geographic distance between the home and the schools also acts as a barrier to learners' involvement in the ethos of the school. African parents' participation in the world of the school is minimal or tokenistic at least.

What the research has generated is migration as a means of inclusion into particular types of schooling. It is also a way which certain groups avoid desegregation by clustering in schools with groups they feel they have more affinity, a form of apartheid by migration. There are four groups of migrating students:

- White learner migration out of schools that are increasingly becoming more Black;

- Indian learner migration out of working-class schools;

- foreign learners who are entering into the South African schooling system;

- African township learners who have experienced schooling in non-township schools and are now returning to the township.

While this study has provided some degree of insight into these phenomena, the scale and scope of this on a macro-scale needs to be investigated further.

One aspect of the research that warrants attention is the link between schools and the community. Schools often operate as if they are independent of the community needs. Little consultation is offered about what courses or curriculum the children should be afforded. As professionals, teachers have jealously guarded this dimension of decision making. A renewed effort should be made to develop understandings of the aspirations of the parent community in relation to the school and its curriculum. For example, working-class parents may share fundamentally different expectations of schooling than the middle-class teachers. Whose agenda becomes the agenda that is imposed on the learners?

Concerted effort should be directed towards building capacity among the managerial staff, to handle the kind of interactions between the parent community and the school. The study revealed that in the better-resourced schools, relatively strong patterns of partnership between the world of school and the world of the home exist. In the wellresourced schools, this involvement is not restricted to only financial support, although this may be a prime motivator for the more conscious involvement of parents. The setting up and sustainability of the role of the school governing body in the schools would need to be monitored more closely.

The lack of involvement and capitulation to the world of school that characterises working-class communities needs to be studied in more depth. Working-class parents are minimally involved in the governance issues of their children's school. Several factors influence this non-participation, but school managers in particular, need to develop particular cooperative skills, which will assist in building the partnership between the parent body and the school.

Language and the issue of English emerge from the entire research project as a key factor in inclusion. Schools clearly need to build capacity around teaching and learning of learners whose first language is not English. A sink-or-swim mentality is currently dominant among schools that have not had prior experience with handling English second language learners. In this regard, a more thorough process of placement of English second language learners into the schooling system of deracialising schools needs to be developed. This would allow teachers and managers, together with parents, to identify the most appropriate placement of their children into the school system. This may take the form of a 'bridging/access' programme. Other possible interventions include the development of an overt language policy within the school, as language policy is often negotiated with the more 
important focus on securing the existing teachers' jobs within the school. The language policy satisfies the teachers rather than the learners. A more conscious effort should be directed towards developing a more centrally led language in education policy, which includes a linking between the learner and staff's home languages. In the absence of a well-developed school language policy, teachers usually resort to explaining underperformance of African learners only in racial stereotyping, rather than linguistic terms.

One aspect of inclusion that has not altered is the teaching profile in that the staffing of school does not reflect the diversity of the learner population. This is partly due to geographic, racialised and apartheid history of South African schools. The study reveals that where schools introduced more diverse staffing, they were subtly marginalised and excluded from unleashing their potential. The adult teachers were more resistant to operating in their enclaves of racial heritage with which apartheid education had made them secure. Schools should be more closely directed in terms of how they could induct managers, teachers and learners into issues of diversity. Simply placing teachers with diverse backgrounds within homogeneous cultures will not be sufficient. The whole community (parents, teachers, managers and learners) needs to be inducted into this new operational stance around diversity.

\section{A key policy issue, which has not received} attention, is the quality of influence that peers have on the learners' performance in schools. How schools manage the voice of their learners in the decision-making processes is thus crucial to developing a shared ethos in the school. Often the learner leadership councils are only tokenistic extensions of the official school perspective. How can schooling be organised in such a way that learners learn to exercise, productively, their democratic voice in the decision-making processes at the school? The voice of the counter-culture within the school is often known and consciously resisted by the officials of the school. However, its insidious influence into the life aspirations of the better learners in the schools needs to be explored even further. What accounts for the fatalistic attitude that characterises working-class learners 'opting out'? Is their opting out to be expected within the climate of loss of faith in education being able to afford them better life chances? What is the link between the world of school and the world of adulthood and the world of work? Do schools focus their operations primarily inwardly to reflect the aspirations and goals of their employers? How are the aspirations of the community given genuine voice in the world of the school?

\section{C o n c luding rem a rks}

This provincial study has only opened up a new terrain of yet unanswered questions. Much of the report's findings seem to reflect a reality about postapartheid schooling that many have known intuitively for some time. This report provides an empirical account of these intuitions. What emerges from the above in regard to developing inclusive education policies are five key issues that the government needs to confront:

- Creating an enabling policy framework is an important step in ensuring inclusion. However, the research has argued that by itself this does not guarantee inclusion. There is a significant policy gap (Sayed 2001) between policy intention and outcome, which the research has pointed out. This requires government to pay more attention to the context of implementation in order to see how policies are diffused at the institutional level and how they are reinterpreted.

- The research points to a real need to review some key aspects of post-1994 policies. In particular, the one key issue that emerges is that of user (school) fees. While there may have been legitimate reasons to allow schools to raise fees following the first democratic election of 1994 , they have generated adverse policy effects, which militate against proper inclusion. Specifically, user fees have bifurcated the system into a two-tier system, with schools serving the well-resourced and those serving the poor. Learner migration is thus mainly possible for those able to do so with the result that there is a particular patent of class and racial clustering of schools in contemporary South Africa. Moreover, the notion of user fees has created inequities in educational provisioning and coupled with soft zoning questions, challenge 
the edifice of inclusionary thrust of postapartheid educational policy.

- The above suggests that for equity to be effected requires greater state intervention in terms of support, capacity development, and resourcing. The voluntarism nature of policy leaves schools with the obvious choice to strategically 'do nothing' as the distortions of the apartheid legacy work in favour of the privileged.

- Clearly the community needs to play a greater role in the school. The formalisation of SGBs through the South African Schools Act needs to be strengthened by creating a more active and vibrant civil society, which can act as a force for transformation and change. The challenges that are being made to user fees suggest such a process is underway. However, this challenge

\section{No t e}

The authors would like to acknowledge the work undertaken by the research team in KwaZulu-Natal including: Shabier Omar, Rita Bansilal, Nyna Amin, Peter Reddy, Labby Ramrathan, Shakila Reddy, Reshma Sookranh, Nirmala Gopal and Daniel Wilson. needs to be broader - it needs to begin to voice the silences in school that learners and teachers experience - the problems of 'not being welcome, being ostracised, etc.' are the silences that need to be highlighted.

- Language emerges as a powerful factor for and against inclusion. Yet it is clear that most schools are not ready or willing to respond appropriately. There is much work to be done in this regard.

The above are some of the key policy issues that have emerged from the research. It is clear that finegrained and textured analyses of schooling provide important pointers to how policies are shaped and reshaped at different levels of the system. They begin to point out how the discourses of inclusion need to be reframed to give effect to laudable policy ideals.

\section{R e ferences}

Carrim, N. and Sayed, Y., 1992, 'Pay as you Learn: Model C Schools are not for Working Class Kids', work in progress, New Era, No 84

Freer, D. (ed), 1999, Towards Open Schools: Possibilities and Realities for Non-racial Education in South Africa, Johannesburg: University of Witwatersrand

Garson, P., 1998, 'The Great School Trek', Siyaya, Issue 2, Winter, Cape Town: University for Democracy in SA

Constitution of the Republic of South Africa, 1996, South Africa: Government Printers

Hoadly, U.K., 1998, 'For Better or Worse: School Choice in a South African Working Context', paper presented at Kenton - SASE Conference, 29 October-1 November 1998, Kei Mouth

Hofmeyer, J., 2000, 'The Emerging School Landscape in Post-apartheid South Africa', paper presented to EASA 'African Renaissance Education', January, Bloemfontein

Mabasa, H., 1997, 'Racial Integration of Public Schools During 1996', Education Monitor, Vol 8 No 2, Pinetown: Education Policy Unit, University of Natal

Naidoo, J.P., 1996, Racial Integration of Public Schools in South Africa-A Study of Practices, Attitudes and Trends, Durban: Education Policy Unit, University of Natal

Paterson, A. and Kruss, G., 1998, 'Educational Migration and its Effects on Access to Schooling in South Africa', South African Journal of Education, Vol 18 No 3: 149-55

Sayed, Y., 2002, 'Education Exclusion and Inclusion in the South: A Review of the Literature', Exclusion and Inclusion Research Project, mimeo, Discussion Paper 1, Brighton: CIE, University of Sussex

Soudien, C., 1998, "We Know Why We Are Here": The Experience of African Children in a "Coloured" School in Cape Town, South Africa', Race Ethnicity Education, Vol 1 No 1: 7-30

Zafar, S., 1999, 'Desegregation in South African Public Schools - Emerging Patterns and Dominant Trends', paper presented at the workshop 'Towards Racial Integration in School', organised by the Department of Education, 31 March-1 April 1999, Pretoria 